\title{
Degradation of widespread pharmaceuticals by activated sludge: Kinetic study, toxicity assessment, and comparison with adsorption processes
}

\author{
Cristina Quintelas*, Daniela P. Mesquita, Ana M. Torres, Isa Costa, Eugénio C. Ferreira \\ CEB - Centre of Biological Engineering, Universidade do Minho, Campus de Gualtar, 4710-057 Braga, Portugal
}

\section{A R T I C L E I N F O}

\section{Keywords:}

Activated sludge

Ibuprofen

Kinetics

Paracetamol

Ecotoxicology

QIA

\begin{abstract}
A B S T R A C T
The growing presence of pharmaceutical compounds in aqueous systems leads to the search for new efficient and eco-friendly solutions to this problem. Although pharmaceutical products are widely found in the aqueous environments, there is limited understanding of their ecological effects. To augment the removal of pharmaceuticals, a bench reactor was inoculated with activated sludge and fed with a synthetic medium. Two pharmaceuticals of widespread usage, ibuprofen (IBU) and paracetamol (PARA) in the range 0.4-1 $\mathrm{mg} \mathrm{L}^{-1}$ were used. The uptake values increased from 0.192 to $0.660 \mathrm{mg} \mathrm{g}^{-1}$ for IBU and from 0.104 to $0.341 \mathrm{mg} \mathrm{g}^{-1}$ for PARA. The removal efficiency reached values from 99.1-99.5\% and is independent of the initial IBU concentration. For PARA the removal percentage ranged from 93.3-98.8 decreasing with the increase on the initial concentration. The removal mechanism is well described by pseudo-first order and pseudo-second order kinetic models for all concentrations tested. At same time, batch assays were performed in order to assess the toxicity of both pharmaceuticals into the activated sludge using quantitative image analysis (QIA). For IBU experiments, QIA studies showed that this compound favors the growth of aggregated biomass rather than filamentous bacteria. A comparison between this biological technology and adsorption by a commercial porous ceramic material and Pinus bark was also performed. The results showed that the biological technology allowed better results $(99.5 \%$ against 19.4 and $9.3 \%$, respectively for the ceramic material and Pinus bark) for IBU. The results obtained for PARA showed comparable results for the biological technology and for adsorption by the ceramic material. The activated sludge system presented here appears to be a promising treatment for pharmaceutical contaminated effluents and the biomass present in the activated sludge seems do not be negatively affected by the presence of high concentrations of both pharmaceuticals.
\end{abstract}

\section{Introduction}

The extensive use of personal care products and pharmaceuticals for human consumption and veterinary usage led to the detection of these products in wastewater effluents and aqueous systems as rivers, surface waters and others. This fact has increased the awareness of the potential threat that pharmaceuticals pose on the aquatic environment [1]. Studies on the occurrence of pharmaceuticals show that the widely used pharmaceuticals ibuprofen (IBU) and paracetamol (PARA) are present in relevant concentrations in the aqueous environment [2-5]. One of the additional problems associated with the release of these compounds to the water streams is that there are no legally regulated maximum permitted concentrations of pharmaceuticals in the environment. Only a few pharmaceuticals, more specifically four substances (macrolide antibiotics, diclofenac, $17 \alpha$-ethynylestradiol, and $17 \beta$-estradiol) were included in the recent watch list of the European Commission [6] for wide monitoring. Biological technologies have been suggested by several authors to remove these compounds from aqueous systems including anaerobic digestion [7], membrane bioreactors [8,9], phytotreatment [10], biodegradation by pure cultures [5,11,12], and activated sludge [13,14]. Physicochemical technologies as activated carbon adsorption [15,16], pine bark and almond shell [17], and clays adsorbents [18,19], ozonation and ozone/activated carbon coupling [20], and chemical oxidation [21] have also been considered. Several disadvantages are associated with physicochemical methods as the generation of secondary pollutants and the high operational costs. The biological methods present less disadvantages: biodegradation of pharmaceuticals is being considered as an environmentally friendly option with low-cost operational requirements and the products of degradation are innocuous end products such as $\mathrm{CO}_{2}$ and $\mathrm{H}_{2} \mathrm{O}$ [22].

The mechanisms involved in the biological removal are mainly adsorption, biotransformation, and degradation [23]. The application

\footnotetext{
* Corresponding author.

E-mail address: cquintelas@deb.uminho.pt (C. Quintelas).
} 
of kinetic models is a worthy tool to study the mechanism that controls the biological process. Several authors applied pseudo-first order and pseudo-second order kinetics models for fitting the experimental biotransformation removal data $[24,25]$. Originally, these models were applied to physical adsorption processes. However, more recently studies have been reported that removal of trace amounts of organic pollutants using activated sludge can be described by a pseudo-first order reaction, due to the relatively low substrate concentration compared to the biomass concentrations [24] or by pseudo-second order kinetics [25].

The ecotoxicology of pharmaceuticals was studied by several authors [26-30]. However, these studies were main focused on the effects on soil organisms and marine flora and fauna and there is a lack of information about the effect of pharmaceuticals on microorganisms namely on activated sludge. Indeed, the effect of these compounds on microorganisms is an important study that should be taken into account when biological processes are used to remove these compounds from aqueous systems. The results of these studies will allow to conclude about the ecotoxicology of the compounds and to establish the range of concentrations where the biomass can be used.

Quantitative image analysis (QIA) has been employed for aggregated and filamentous bacteria contents determination, biomass structure and physiology [31]. Accordingly to these authors, image processing and analysis methodologies are able to provide valuable information about activated sludge systems, and can be recognized as valid monitoring tools. This technology allows to detect bulking phenomena and to prevent sedimentation problems.

The aims of the present study were: (i) to evaluate the potential of a bioreactor inoculated with activated sludge, for removing pharmaceuticals from wastewater and compare the behavior of this bioreactor with physicochemical methods (adsorption by a porous ceramic material and pinus bark); (ii) to determine the rate kinetic parameters of pseudo-first and pseudo-second order models for the removal of pharmaceutical compounds onto activated sludge biomass; and (iii) to analyze the effects of IBU and PARA on the biomass morphology using quantitative image analysis (QIA). Usually the removal of paracetamol using microorganisms is performed using pure cultures [12] and the use of conventional activated sludge wastewater treatment is considered inadequate for the effective removal of many emerging trace organic contaminants [32]. This research aims to show that the use of activated sludge (microbial consortium) presents several advantages over the use of pure cultures to remove paracetamol and ibuprofen. It is imperative to stimulate water reuse, and the complete removal of emerging contaminants, as pharmaceuticals, from wastewater will contribute to this aim. The use of QIA to analyze the effects of the pharmaceuticals on the biomass is also a novelty of this study. This team believes that the successful execution of these objectives will contribute to fill the knowledge gap that exists in the field of the removal of pharmaceuticals by activated sludge.

\section{Materials and methods}

\subsection{Selection, main characteristics and preparation of pharmaceuticals}

The pharmaceuticals chosen for this study are high consumption drugs. Paracetamol is one of the most commonly used oral analgesics and antipyretics and ibuprofen is an anti-inflammatory of widespread usage. Both substances are extensively used as non-prescription medicine, with an annual consumption of hundreds of tons around the world [33]. Both pharmaceutical products were of the highest purity commercially available. IBU was purchased from Acros Organics and PARA was purchased from Sigma-Aldrich. The main characteristics of both pharmaceuticals are presented in Table SM-1 (Supplementary material). A stock solution of each pharmaceutical was prepared from powdered substances in distilled water at a concentration of $20 \mathrm{mg} \mathrm{L}^{-1}$ and then stored at $4{ }^{\circ} \mathrm{C}$. This stock solution was then diluted to the working concentrations.

\subsection{Experimental unit and procedure}

\subsubsection{Removal and kinetics assays}

Experiments with different ibuprofen (IBU) and paracetamol (PARA) concentrations $\left(0.4,0.5,0.6,0.8\right.$, and $\left.1.0 \mathrm{mg} \mathrm{L}^{-1}\right)$ were conducted in a $4 \mathrm{~L}$ lab-scale batch reactor operated at room temperature during approximately three days. Although the concentrations found in the environment are in the $\mathrm{ng} / \mathrm{L}-\mu \mathrm{g} / \mathrm{L}$ range, higher concentrations are found in wastewater originated from hospitals or elderly houses [34]. In what concerns to Portugal, ibuprofen consumption has been increasing during the last decade, moving from the 15th to 8th position in the sales ranking [35]. Considering the increase on the consumption of nonprescribed drugs, as ibuprofen and paracetamol, and taking into account the presence of higher concentrations on specific locations the authors decided to test the reactor for concentrations in the range $0.4-1 \mathrm{mg} / \mathrm{L}$. The system was inoculated with activated sludge from a domestic wastewater treatment plant where an initial mixed liquor suspended solids (MLSS) concentration of $3 \mathrm{~g} \mathrm{~L}^{-1}$ was used. A synthetic medium was fed to the system in the beginning of each experiment and contained (per liter): $2.55 \mathrm{~g} \mathrm{C}_{2} \mathrm{H}_{3} \mathrm{O}_{2} \mathrm{Na} .3 \mathrm{H}_{2} \mathrm{O}, 0.34 \mathrm{~g} \mathrm{C}_{3} \mathrm{H}_{5} \mathrm{NaO}_{2}, 0.59 \mathrm{~g}$ $\mathrm{NH}_{4} \mathrm{Cl}, 0.95 \mathrm{~g} \mathrm{MgSO}_{4} \cdot 7 \mathrm{H}_{2} \mathrm{O}, 0.44 \mathrm{~g} \mathrm{CaCl}_{2} \cdot 2 \mathrm{H}_{2} \mathrm{O}, 0.03 \mathrm{~g}$ EDTA, and $3.16 \mathrm{~mL}$ of a trace metals solution. The trace metals solution was well described by Smolders et al. [36]. Compressed air was used to ensure aerobic conditions and the $\mathrm{pH}$ was maintained around 7 by a $\mathrm{pH}$ controller using two-way controller pumps dosing $0.3 \mathrm{M} \mathrm{HCl}$ or $0.3 \mathrm{M}$ $\mathrm{NaOH}$ when the $\mathrm{pH}$ was above/below the set point. The agitation was kept constant at $150 \mathrm{rpm}$. Samples were taken at different time intervals, centrifuged $(13,400 \mathrm{rpm}$ for $10 \mathrm{~min})$ and the aqueous phase was stored at $4{ }^{\circ} \mathrm{C}$. Prior to analysis, the liquid samples were thawed and homogenized by vortexing. The IBU and PARA concentrations were determined using a UHPLC system. All measurements were conducted in duplicate. The results presented are an average of both results. The relative standard deviation and relative error of the experimental measurements were $<1 \%$ and $3 \%$, respectively.

\subsubsection{Adsorption assays}

For comparison reasons the same $4 \mathrm{~L}$ reactor used for the biological treatment was used for adsorption assays. These assays were performed using porous ceramic material (diameter $8-16 \mathrm{~mm}$ and $274 \mathrm{~kg} \mathrm{~m}^{-3}$ of density) and pinus bark (diameter $1-5 \mathrm{~mm}$ and $1377 \mathrm{~kg} \mathrm{~m}^{-3}$ of density) as adsorbents, for an initial concentration of IBU and PARA of $1 \mathrm{mg} \mathrm{L}^{-1}$ (4 L of pharmaceutical compound solution, $30 \mathrm{~g}$ of adsorbent, $150 \mathrm{rpm}$, at room temperature). Samples were taken at different time intervals, centrifuged (13,400 rpm for $10 \mathrm{~min}$ ) and the aqueous phase was stored at $4{ }^{\circ} \mathrm{C}$. Prior to analysis, the liquid samples were thawed and homogenized by vortexing. The IBU and PARA concentrations were determined using a UHPLC system. All measurements were conducted in duplicate. The results presented are an average of both results. The relative standard deviation and relative error of the experimental measurements were $<1 \%$ and $3 \%$, respectively.

\subsubsection{Ecotoxicity assessment}

To analyze morphological changes and ecotoxicology of IBU and PARA, four identical batch reactors ( $300 \mathrm{~mL}$ working volume) were used during $24 \mathrm{~h}$, at room temperature and agitated at $150 \mathrm{rpm}$. The reactors were inoculated with activated sludge from a domestic wastewater treatment plant (MLSS $=3 \mathrm{~g} \mathrm{~L}^{-1}$ ) and the initial concentrations of IBU/PARA were 1,10 , and $20 \mathrm{mg} \mathrm{L}^{-1}$. A control batch, without IBU/ PARA, was also analyzed. The synthetic medium used was previously presented in Section 2.2.1. Aggregated and filamentous biomass contents and structure were assessed by images acquired through brightfield microscopy from MLSS samples obtained in each experiment. Samples were taken from the batch reactors for visualization and image acquisition in five periods of time using an Olympus BX51 microscope 
(Olympus, Tokyo, Japan) coupled with an Olympus DP71 camera (Olympus, Tokyo, Japan). A recalibrated micropipette with a sectioned tip at the end, with a large enough diameter to allow larger aggregates to flow, was used to deposit $10 \mu \mathrm{L}$ of the sample on to the slide, and covered with a $20 \mathrm{~mm} \times 20 \mathrm{~mm}$ cover slip. Three slides per sample were used taking 50 images per slide resulting in 150 images. Samples were examined at $100 \mathrm{x}$ total magnification and acquired at $1360 \times 1024$ pixels in 8-bit format. Images were acquired in the upper, middle and bottom of the slide to improve the representativeness of the microbial community. The QIA results presented are an average of the 150 images acquired.

\subsection{Analytical details}

\subsubsection{Pharmaceuticals analysis by UHPLC}

Chromatographic analysis was performed using a Shimadzu Corporation apparatus (Tokyo, Japan) consisting of a UHPLC equipment (Nexera) with one multi-channel pump (LC-30AD), an autosampler (SIL-30AC), an oven (CTO-20AC), a diode array detector (M20A) and a system controller (CBM-20A) with proper software (LabSolutions). For ibuprofen, a Kinetex5 u EVO C18 column (150×4.6 mm i.d.) supplied by Phenomenex, Inc. (CA, USA) was used. The mobile phase was sodium phosphate ( $20 \mathrm{mM}$; pH 2.4) (pump A) and acetonitrile (pump B). Starting mobile phase composition was $80 \%$ $\mathrm{A}$, decreased to $30 \% \mathrm{~A}$ in $10 \mathrm{~min}$ and remains in this percentage for $5 \mathrm{~min}$. The flow rate was $1.5 \mathrm{~mL} \mathrm{~min}^{-1}$. The sample was monitored by the diode array detector from 190 to $400 \mathrm{~nm}$, and chromatograms were extracted at $225 \mathrm{~nm}$. Column oven was set at $40^{\circ} \mathrm{C}$ and the volume of injection was $10 \mu \mathrm{L}$. For solid phase extraction (SPE), the sorbent cartridges (Strata SDB-L Styrene-Divinylbenzene Polymer, $100 \mathrm{mg} / 1 \mathrm{~mL}$ ) were used. The cartridges were conditioned with acetonitrile and equilibrated with water. The sample was loaded and washed with methanol/water (30:70), dried 10 min under full vacuum and eluted with acetonitrile. For paracetamol, a Kinetex 2.6 u EVO C18 column (150×4.6 mm i.d.) supplied by Phenomenex, Inc. (CA, USA) was used. The mobile phase was $0.1 \%$ phosphoric acid in water (pump A) and 0.1 $\%$ phosphoric acid in acetonitrile (pump B). Starting mobile phase composition was $95 \% \mathrm{~A}$, decreased to $5 \% \mathrm{~A}$ in $9 \mathrm{~min}$ and increased again to $95 \%$ (9.01 $\mathrm{min}$ ) and remains in this percentage for $3 \mathrm{~min}$. The flow rate was $1.8 \mathrm{~mL} / \mathrm{min}$. The sample was monitored by the diode array detector from 190 to $400 \mathrm{~nm}$, and chromatograms were extracted at $215 \mathrm{~nm}$. Column oven was set at $50^{\circ} \mathrm{C}$ and the volume of injection was $5 \mu \mathrm{L}$. For solid phase extraction (SPE), the sorbent cartridges (Strata SDB-L Styrene-Divinylbenzene Polymer, $100 \mathrm{mg} / 1 \mathrm{~mL}$ ) were used. The cartridges were conditioned with methanol and equilibrated with water. The sample was loaded and washed with methanol/water (5:95), dried 10 min under full vacuum and eluted with methanol.

\subsubsection{Quantitative image analysis (QIA)}

2.3.2.1. Image processing and analysis in bright-field images. Bright field program was developed in Matlab 7.3 (The Mathworks, Natick, USA) for the recognition of aggregates and filamentous bacteria in grayscale images. A more detailed description of the image processing methodology can be found in Mesquita et al. [31]. Fig. 1 shows an illustrative bright-field image with corresponding aggregates and filaments binary images obtained from the QIA procedure.

2.3.2.2. Morphological parameters determination. Aggregates were classified according to their size in: small aggregates (Deq $<25 \mu \mathrm{m}$ ); intermediate aggregates $(25<$ Deq $<250 \mu \mathrm{m})$; and large aggregates (Deq $>250 \mu \mathrm{m}$ ), where Deq represents the equivalent diameter. For each studied class, the aggregates area percentage was calculated. The aggregates total area per volume (TA/Vol) and filaments total length per volume (TL/Vol) were also determined according to Mesquita et al. [37].

\section{Results and discussion}

\subsection{Ibuprofen and Paracetamol removal performance by activated sludge} and comparison with adsorption processes

In recent years, several reports about pharmaceuticals detected in a variety of environmental samples, as river water, seawater, and wastewater were published $[35,38,39]$ proving that much scientific attention is being focused in the occurrence of pharmaceuticals in the environment. The present study shows that a reactor inoculated with activated sludge is able to remove IBU in percentages around $99 \%$ whereas PARA was removed between 93.3 and $98.8 \%$. The pharmaceuticals were aerobically degraded by the biomass or sorbed to the solids, with IBU being faster removed than PARA (Fig. 2). Ibuprofen was removed within $50 \mathrm{~h}$ to undetectable concentrations and paracetamol was removed to acceptable levels in approximately $73-77 \mathrm{~h}$. For IBU, the largest amount of this pharmaceutical was removed in $6-10 \mathrm{~h}$. This quick removal may indicate not only biodegradation but also external sorption sites on the solids for IBU removal from water [40]. The removal of PARA was slower, for the concentration of $0.4 \mathrm{mg} / \mathrm{L}$ the largest amount of PARA was removed on the first $29 \mathrm{~h}$ and for the highest concentration, $1 \mathrm{mg} / \mathrm{L}$, the time to reached equilibrium was more than $73 \mathrm{~h}$. The uptake rates and removal percentages are presented in Table 1 . The uptake varied from $0.192 \mathrm{mgg}^{-1}$ to $0.660 \mathrm{mg} \mathrm{g}^{-1}$ for IBU and from $0.104 \mathrm{mg} \mathrm{g}^{-1}$ to $0.341 \mathrm{mg} / \mathrm{g}$ for PARA. As expected the uptake increase with the increase on the pharmaceutical concentration. Different authors suggested that this behavior could be justified by the fact that surface saturation was dependent on the initial pharmaceutical concentration [41]. As the concentration increase, the number of moles of IBU/PARA also increased for the same amount of available sites on the biomass. The removal percentage is similar for all the initial concentrations tested for IBU. The removal percentage around $99 \%$ for IBU suggests that this activated sludge system could be used to remove higher concentrations of IBU than those tested in this assays. In fact, the biomass seems to be far from the maximum removal capacity. For PARA, the removal percentage decrease with the increase on the initial PARA concentration. This behavior can be explained easily: higher concentrations reduce the average distance between the


Fig. 1. (a) original grayscale image, (b) aggregates binary image, (c) filaments binary image. 


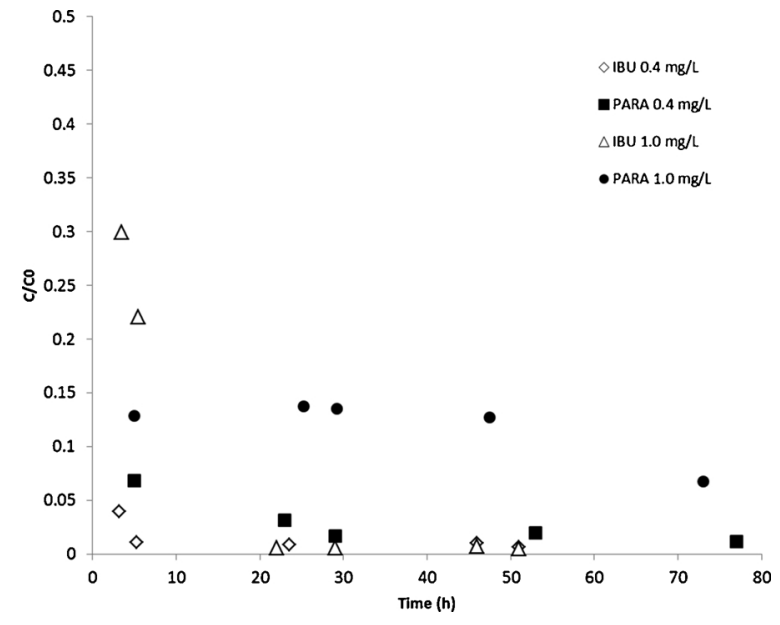

Fig. 2. Ratio between residual and initial pharmaceutical concentration $(\mathrm{C} / \mathrm{C} 0)$ as a function of contact time, for the initial concentrations of 0.4 and $1 \mathrm{mg} \mathrm{L}^{-1}$ (Data not shown for $t_{0}$ ).

Table 1

Values of removal percentage (\%) and $\mathrm{q}_{\mathrm{e}}\left(\mathrm{mg} \mathrm{g}^{-1}\right)$ calculated for different initial concentration of IBU and PARA using a reactor inoculated with activated sludge.

\begin{tabular}{llllll}
\hline \multirow{2}{*}{$\operatorname{Ci}\left(\mathrm{mg} \mathrm{L}^{-1}\right)$} & \multicolumn{2}{l}{$\%$ Removal } & & & \multicolumn{2}{l}{ Uptake } \\
\cline { 2 - 3 } \cline { 5 - 6 } & IBU & PARA & & IBU & PARA \\
\hline 0.4 & 99.33 & 98.84 & & 0.192 & 0.104 \\
0.5 & 99.06 & 97.86 & & 0.228 & 0.170 \\
0.6 & 99.49 & 95.83 & & 0.312 & 0.168 \\
0.8 & 99.45 & 94.75 & & 0.365 & 0.325 \\
1.0 & 99.47 & 93.25 & & 0.660 & 0.341 \\
\hline
\end{tabular}

adsorbing species and this affect the charge distribution of all the species involved and alter the capacity of the species to migrate to the biomass surface, resulting in reduced adsorption [42]. For this compound, the lower removal percentage obtained was $93.3 \%(\mathrm{Ci}=1 \mathrm{mg} \mathrm{L}$ ${ }^{1}$ ) in $73 \mathrm{~h}$. This result indicates that, as for IBU, the system could be used to treat higher concentration of PARA, however the time required to reach the equilibrium will be higher what could be a disadvantage. The difference on the removal percentage and uptake of IBU and PARA indicates that the microbial populations in the inoculum show a different affinity towards the degradation of the selected pharmaceuticals.

The mechanisms involved in the removal of pharmaceuticals by microorganisms include biodegradation, bio-sorption, volatilization and hydrolysis [43]. Ibuprofen and paracetamol are usually resistant to hydrolysis, because they are designed for oral intake [44]. Ibuprofen is not significantly volatilized in the activated sludge [14] and is known for its easy biodegradability [34] suggesting that the main mechanisms involved in the removal of IBU are biodegradation and bio-sorption. Paracetamol is also mainly degraded by microorganisms [22] or by sorption to solids and biodegradation when an activated sludge system is used. Indeed, both mechanisms, biodegradation and sorption to the solids, were responsible for IBU/PARA removal on activated sludge, resulting in a large IBU/PARA removal capacity of about $66 \%$ by weight and $34 \%$ by weight, respectively for the highest concentration of IBU and PARA. Several authors tested the use of biomass, activated sludge or other biological systems, to remove IBU and PARA. Carballa et al. [45] obtained removal percentages of IBU around $40 \%$ using an anaerobic activated sludge system; Nakada et al. [46] achieved $90 \%$ of IBU removal during activated sludge treatment; and Langenhoff et al. [34] obtained the complete removal of IBU, in 4 days, using activated sludge from a pilot plant treating hospital wastewater. The aerobic degradation of IBU by an indigenous bacterial community was tested by
Fortunato et al. [47]. These authors found removal percentages around $99 \%$ (33 h, $100 \mathrm{mg} \mathrm{L}^{-1}$ initial concentration), proving the ability of the indigenous communities to improve the treatment of wastewaters containing IBU. Biodegradation and bio-sorption of both, IBU and PARA, was analyzed by Yu et al. [43] using immobilized cell process. The removal of approximately $100 \%$ PARA was achieved via biosorption or sorption within $8 \mathrm{~d}$ and more than $25 \%$ PARA removed by biodegradation within 2 d. For IBU, $77 \%$ was removed via biodegradation in $4 \mathrm{~d}$ and $28 \%$ via bio-sorption in $14 \mathrm{~d}$. Zhang et al. [12] studied the removal of PARA by pure bacterial cultures and their microbial consortium and found that the consortium of three microbial strains recovered from the same culture was shown to be necessary for complete PARA degradation and mineralization, suggesting a possible complementary interaction among the various isolates. The system used in the present study allows high efficiency in a shorter period.

The biodegradation of IBU and PARA was well studied by several authors [13,22,48,49]. Accordingly to Zwiener et al. [48], IBU is transformed in ibuprofen carboxylic acid (CBX-IBU) and hydroxylated ibuprofen (oxic conditions), and only in CBX IBU (anoxic conditions). These authors concluded that only $10 \%$ of ibuprofen removed could be attributed to its transformation into these metabolites. Other authors detected two isomers of hydroxy-ibuprofen (2-OH IBU and 1-OH IBU) as intermediates in the mineralization of ibuprofen by microorganisms and concluded that both intermediates were also degraded or disappeared quickly from the bioreactor [49]. Paracetamol is mainly degraded to 4-aminophenol and hydroquinone [12]. As reported by other authors some intermediates (not identified) appeared during the UHPLC analysis after some hours of experiment. The presence of intermediates proves that PARA and IBU are being degraded. These intermediates disappeared during the experiment meaning that they were also degraded by the activated sludge biomass.

The removal of IBU and PARA was also tested using adsorbents aiming to compare the behavior of biological methods and physicochemical methods. A porous ceramic material, mainly constituted by expanded clay material, and pinus bark were selected as adsorbents. Porous ceramic materials were already used in the treatment of wastewater contaminated with IBU $[50,51]$ and Pinus bark was used for the removal of steroids [17] and bisphenol A [52]. The removal percentages obtained for the removal by expanded clays are $19.4 \%$ and 97.5 $\%$, respectively for IBU and PARA as reported in Table 2 . The difference between the removal percentages for both pharmaceuticals seems to be related with the size of the molecule. Ibuprofen has a molecular weight of $206.3 \mathrm{~g} \mathrm{~mol}^{-1}$ and paracetamol has a molecular weight of $151.2 \mathrm{~g}$ $\mathrm{mol}^{-1}$. The molecules of IBU are too large for the porous of ceramic material and the entrapment of this compound is more difficult. The removal percentage of $19.4 \%$ obtained is related with the adsorption of IBU by adsorption sites on the material surface. Behera et al. [53] used different clays (kaolinite, montmorillonite, goethite) to remove IBU and obtained removal percentages between $4-12 \%\left(\mathrm{Ci}=60 \mathrm{mg} \mathrm{L}^{-1}\right)$. On the other hand, Dordio et al. [50] used a matrix of light expanded clay aggregates (LECA) planted with Typha spp. to remove IBU and obtained removal percentages of $96 \%$ proving that the lower removal percentages obtained when clays materials are used could be incremented by combination with biological treatment.

Pinus bark was also used as adsorbent and obtained $9.3 \%$ and 20.5

Table 2

Values of removal percentage (\%) and $\mathrm{q}_{\mathrm{e}}\left(\mathrm{mg} \mathrm{g}^{-1}\right)$ using ceramic material and Pinus bark adsorbents, for an initial concentration of $1 \mathrm{mg} \mathrm{L}^{-1}$ of IBU and PARA pharmaceuticals.

\begin{tabular}{llllll}
\hline Adsorbent & \multicolumn{2}{l}{$\%$ Removal } & & & \multicolumn{2}{l}{ Uptake } \\
\cline { 2 - 3 } \cline { 5 - 6 } & IBU & PARA & & IBU & PARA \\
\hline Ceramic Material & 19.42 & 97.47 & & 0.067 & 0.217 \\
Pinus Bark & 9.28 & 20.47 & & 0.024 & 0.067 \\
\hline
\end{tabular}


$\%$ removal percentages, respectively for IBU and PARA. The results obtained for Pinus bark as adsorbent are worse than the obtained using ceramic material as adsorbent. This can be related to the porous structure of both materials. Expanded clay materials are well known for its mesoporous structure [54], which allows better results.

From the analysis of Tables 1 and 2, it is possible to conclude that the use of a biological method (activated sludge) presents better results than the obtained using a physicochemical method (ceramic material and Pinus bark as adsorbents), for IBU. For PARA, the removal obtained for the biological method is comparable to the obtained using ceramic material as adsorbent. However, the results are worst for Pinus bark.

As the use of biological methods presents several advantages over the use of adsorption, as already explained in introduction section, the use of activated sludge is also an attractive method from the economical point of view. Although the adsorbent materials tested, pinus bark and ceramic material are relatively inexpensive, they have a higher cost than activated sludge biomass. These findings reinforce our opinion that this system is very promising in the treatment of water contaminated with high concentration of pharmaceuticals.

\subsection{Ibuprofen and paracetamol removal kinetics}

Kinetic modeling must be taken into account to develop suitable mathematical models for predicting the performance of treatment systems. Aiming to study the process of removal of the selected pharmaceuticals, two simplified kinetic models, namely pseudo-first order and pseudo-second order, were used to study the mechanism that controls the biological process. The nonlinear forms of both equations [55] are respectively expressed as:

$q=q_{e}\left(1-e^{-k_{1} t}\right)$

$q=\frac{k_{2} q_{e}^{2} t}{1+k_{2} q_{e} t}$

The value of $q_{\mathrm{e}}$ represents the amount (uptake) adsorbed onto adsorbent at equilibrium ( $\mathrm{mg} \mathrm{g}^{-1}$ ), $k_{1}$ and $k_{2}$ are rate sorption constants, and $t$ is time. The values of $k_{1}$ and $k_{2}$, and predicted $q_{\mathrm{e}}$ uptakes are presented in Tables 3 and 4 . For IBU, the values of $k_{1}$ and $k_{2}$ decrease as the initial concentration increase (except for $0.8 \mathrm{mg} \mathrm{L}^{-1}$ ), which means that the removal becomes slower as the concentration increases. For PARA, the values of $k_{1}$ and $k_{2}$ do not follow any trend.

The comparison between the experimental results and those predicted by both models is shown in Fig. 3(a-d). The analysis of Fig. 3 and the correlation coefficients $\left(\mathrm{R}^{2}\right)$ (values not shown) suggest that both models, pseudo-first order and pseudo-second order models, fits well the removal of IBU and PARA by the reactor inoculated with activated sludge. Accordingly to Garcia-Rodrigues et al. [64] a good fit to the pseudo-first order model should be related to the effect of biodegradation processes, generally described as first order reactions. The assumptions of both models are different: pseudo-first order models assumes that the reaction rate is limited by one mechanism, one class of

Table 3

Rate kinetic parameters of pseudo-first and pseudo-second order models for the removal of ibuprofen at different initial concentrations, onto activated sludge biomass.

\begin{tabular}{lllllll}
\hline $\begin{array}{l}\mathrm{C}_{\mathrm{i}} \\
(\mathrm{mg}\end{array}$ & $\mathrm{q}_{\mathrm{e}}\left(\mathrm{mg} \mathrm{g}^{-1}\right)$ & & & \multirow{2}{*}{$\mathrm{k}_{1}\left(\mathrm{~h}^{-1}\right)$} & $\begin{array}{l}\mathrm{k}_{2}(\mathrm{~g} \\
\mathrm{mg}^{-1} \mathrm{~h}^{-}\end{array}$ & $\mathrm{R}_{\mathrm{W}}$ \\
\cline { 2 - 6 } $\left.\mathrm{L}^{-1}\right)$ & Experimental & $\begin{array}{l}\text { predicted } \\
\text { (1 st order) }\end{array}$ & $\begin{array}{l}\text { predicted } \\
\text { (2nd order) }\end{array}$ & & & \\
\hline 0.4 & 0.192 & 0.192 & 0.193 & 1.063 & 53.605 & 0.0019 \\
0.5 & 0.228 & 0.228 & 0.232 & 0.606 & 4.785 & 0.0174 \\
0.6 & 0.312 & 0.311 & 0.321 & 0.387 & 2.725 & 0.0218 \\
0.8 & 0.365 & 0.363 & 0.373 & 0.447 & 3.255 & 0.0157 \\
1.0 & 0.660 & 0.657 & 0.698 & 0.320 & 0.798 & 0.0340 \\
\hline
\end{tabular}

Table 4

Rate kinetic parameters of pseudo-first and pseudo-second order models for the removal of paracetamol at different initial concentrations, onto activated sludge biomass.

\begin{tabular}{lllllll}
\hline $\begin{array}{l}\mathrm{C}_{\mathrm{i}} \\
(\mathrm{mg}\end{array}$ & $\mathrm{q}_{\mathrm{e}}\left(\mathrm{mg} \mathrm{g}^{-1}\right)$ & & \multicolumn{5}{c}{$\mathrm{k}_{1}\left(\mathrm{~h}^{-1}\right)$} & $\mathrm{k}_{2}(\mathrm{~g} \mathrm{mg}$ \\
$\left.\mathrm{L}^{-1}\right)$ & Experimental & $\begin{array}{l}\text { predicted } \\
\text { (1 st order) }\end{array}$ & $\begin{array}{l}\text { predicted } \\
\text { (2nd order) }\end{array}$ & & & \\
\hline 0.4 & 0.104 & 0.104 & 0.104 & 0.601 & 30.771 & 0.0426 \\
0.5 & 0.170 & 0.170 & 0.170 & 0.647 & 37.008 & 0.0021 \\
0.6 & 0.168 & 0.168 & 0.167 & 0.387 & 54.337 & 0.0014 \\
0.8 & 0.325 & 0.321 & 0.321 & 1.401 & 124.317 & 0.0003 \\
1.0 & 0.341 & 0.323 & 0.325 & 0.863 & 24.322 & 0.0017 \\
\hline
\end{tabular}
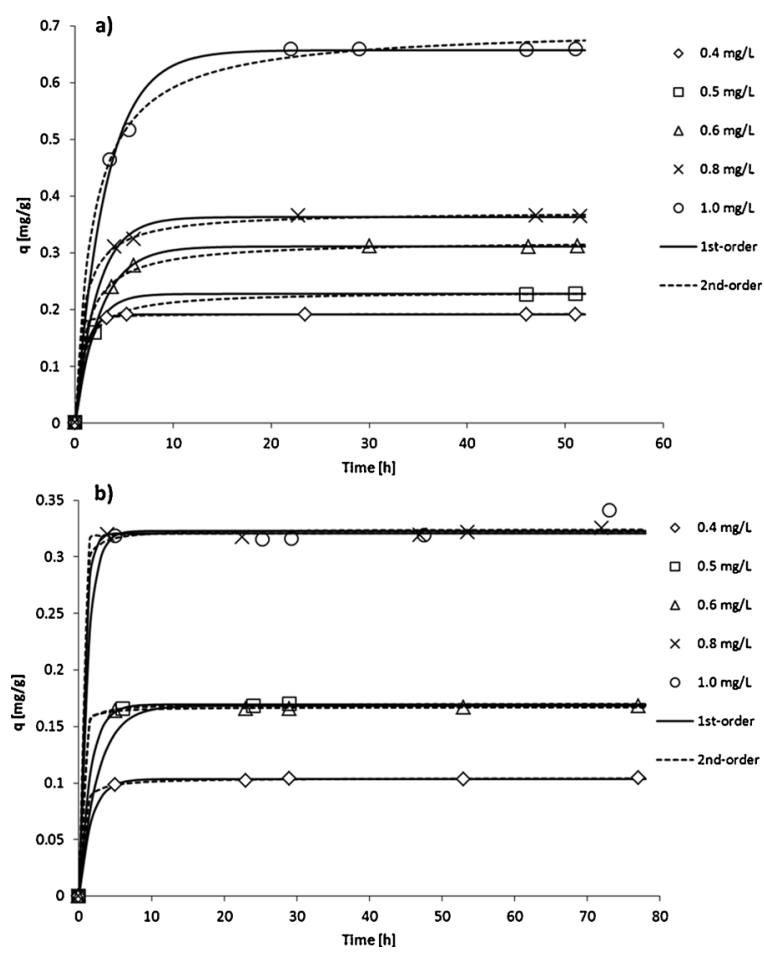

Fig. 3. Pseudo-first order and pseudo-second order kinetics plots for removal of a) IBU and b) PARA by activated sludge.

sorbing sites and all of them of time dependent type; pseudo-second order model assumes that the adsorption process is controlled by surface reaction, with chemisorption involving valence forces, through sharing or exchange of electrons between bacteria and pharmaceutical compounds [56]. Results indicate that a mixed of both removal processes are involved in the removal of IBU/PARA by the activated sludge. The calculated $q_{\mathrm{e}}$ uptakes agree with the experimental data, especially for the lower concentrations and for both models. Other important parameter, named approaching equilibrium factor $\left(R_{\mathrm{w}}\right)$ (Eq. 3 ), was proposed by Ofomaja [57]. These authors studied the relationship between pseudo-second order parameters and the removal performance by the analysis of the characteristic kinetic curve. The equilibrium factor is expressed as:

$R_{W}=\frac{1}{1+k_{2} q_{e} t_{r e f}}$

where $t_{\text {ref }}$ is the longest operation time (based on kinetic experiments). Values of $R_{\mathrm{w}}=1$ represent a linear type kinetic curve which means that the process is not approaching equilibrium. Values of $R_{\mathrm{w}}$ between $0.1-1$ indicate a kinetic curve slightly curved, approaching equilibrium; between 0.01-0.1 represent a kinetic curve largely curved, well approaching equilibrium; and values lower than 0.01 indicate a kinetic 
curve pseudo-rectangular, drastically approaching equilibrium. In this study, the values for $R_{\mathrm{w}}$ shown in Tables 3 and 4 were found to range between 0.001 and 0.03 , confirming the good performance of the system used.

Garcia-Rodrigues et al. [Garcia-Rodrigues et al., 2015] tested the biodegradation of several pharmaceuticals including IBU and PARA using two aquatic plants (Lemna sp. and Spirogyra sp.) and reported that the best fit was obtained using pseudo-first order model with values of $k_{1}$ of 0.132 day $^{-1}$ and 0.479 day $^{-1}$, respectively using Spirogyra sp. and Lemna sp., for PARA, 0.099 day $^{-1}$ and 0.109 day $^{-1}$, respectively using Spirogyra sp. and Lemna sp., for IBU. Santaeufémia et al. [58] studied the removal of IBU using microalga Phaeodactylum tricornutum and found that the pseudo-second order kinetic model was the most suitable for the description of the ibuprofen sorption using this microalga with values of $\mathrm{k}_{2}$ of $2.92 \mathrm{~g} \mathrm{mg}^{-1} \mathrm{~h}^{-1}$ and $2.61 \mathrm{~g} \mathrm{mg}^{-1} \mathrm{~h}^{-1}$, respectively for living and dead forms of the microalga. In the present work, the values obtained for the kinetic constants are higher which indicates a faster removal. These results contribute to highlight the good performance of the reactor.

\subsection{Ibuprofen and Paracetamol effects on the biomass}

Microscopic examination of aerobic sludge has been useful for determining the physical nature of the biomass structure, and the type and abundance of aggregated and filamentous microorganisms. Coupled to microscopy survey and advances in digital imaging acquisition and computer processing capabilities allow for a fast and efficient classification and quantification of the biomass. Thus, image processing and analysis is, at present, a well-established technique for biological processes monitoring when combined to bright-field and/or fluorescent microscopy. Amongst other applications, quantitative image analysis (QIA) has been used to identify activated sludge disturbances [59], detect filamentous bulking problems [60], and predict the sludge settleability [61]. However, QIA studies for studying the effects of different concentrations of pharmaceuticals in aggregated and filamentous microorganisms are still lacking.

In this study, the automatic identification and quantification of aggregated and filamentous microorganisms was sought using QIA. The experiments were conducted through $24 \mathrm{~h}$ using different concentrations of IBU and PARA in order to investigate its effects on the biomass structure during a short period. The results here presented were normalized by the control experimental data without the addition of pharmaceuticals. Furthermore, the size distribution of aggregated biomass was also studied regarding the percentage of small (Deq $<25 \mu \mathrm{m}$ ) and intermediate $(25<\mathrm{Deq}<250 \mu \mathrm{m})$, since no large aggregates (Deq $>250 \mu \mathrm{m}$ ) were found in the samples.

During the experiment with 1,10 , and $20 \mathrm{mg} \mathrm{L}^{-1}$ of PARA, in spite of a slight variation, the aggregates area ratio (small and intermediate) (Fig. 4a, c) tended to the initial value, indicating that these experiments presented the same trend as the control. These results showed that no effects were found in the biomass structure during the experiments with different PARA concentrations. The study conducted by Lawrence et al. [62] showed that no significant impact was found in bacterial biomass that corroborates the findings of the present work.

Regarding the structure of the biomass during the experiment with $1 \mathrm{mg} \mathrm{L}^{-1}$ of IBU, it can be seen that the effect of aggregates fragmentation is extensively higher than with the same concentration of PARA. In this case, the small aggregates area percentage increased from $36 \%$ to $53 \%$ (Fig. 4b) and the intermediate aggregates percentage decreased from $62 \%$ to $39 \%$ (Fig. 4d). Considering the experiments using 10 and $20 \mathrm{mg} \mathrm{L}^{-1}$ of IBU, it was found that the breakage of intermediate to small aggregates was considerably greater when all the experimental data were compared. The small aggregates area percentage increased from $36 \%$ at the beginning of both experiments to $68 \%$ and $80 \%$, respectively (Fig. 4b). The intermediate aggregates area percentage decreased significantly from $62 \%$ to $28 \%$ when $10 \mathrm{mg} \mathrm{L}^{-1}$ of IBU was added and from $62 \%$ to $17 \%$ using $20 \mathrm{mg} \mathrm{L}^{-1}$ of IBU (Fig. 4d). It seems therefore clear that IBU presents substantial effect in bacterial biomass leading a deflocculating phenomenon with higher impact for 10 and $20 \mathrm{mg} \mathrm{L}^{-1}$.

The aggregates total area (TA/Vol) and filaments total length (TL/ Vol) contents were also studied as shown in Fig. 5(a-d). For all the concentrations tested with PARA, the TA/Vol parameter was quite similar (Fig. 5a). These results revealed that the same trend was achieved for all the experiments with the different concentrations of PARA and for the control. The TL/Vol presented a stable ratio for the experiment with $1 \mathrm{mg} \mathrm{L}^{-1}$ of PARA, indicating that the results for the lowest concentration were similar to the control results. Regarding the highest concentrations, it can be concluded that $20 \mathrm{mg} \mathrm{L}^{-1}$ of PARA slightly favored the growth of filamentous bacteria rather than aggregated biomass (Fig. 5c).

The behavior of TA/Vol ratio for 1,10 and $20 \mathrm{mg} \mathrm{L}^{-1}$ of IBU revealed an increase for all the experiments (Fig. $5 \mathrm{~b}$ ). This could be explained by the lowest TA/Vol reached during the control experiment. The filamentous bacteria contents (TL/Vol) presented a decrease for all the concentrations studied (Fig. 5d). It seems therefore clear that IBU favors the growth of aggregated biomass rather than filamentous bacteria. Caracciolo et al. [63] reported that IBU was found to reduce the overall bacteria of biofilm communities. However, in the present work this effect was observed just for the filamentous bacteria community considering the decrease of TL/Vol throughout the experiments.

Although the acute ecotoxicity of ibuprofen and paracetamol is relatively limited, it definitely poses a risk on the ecosystems and more studies on effective removal of these pharmaceuticals are needed.

The fast IBU/PARA removal, large IBU/PARA removal capacity, and negligible ecotoxicological effects of both pharmaceuticals on the biomass, allow to classify the activated sludge as good material to remove IBU/PARA from wastewater contributing to an environmental friendly solution for the problems of pharmaceuticals. This system is very promising and can be tested for other pharmaceuticals.

\section{Conclusions}

This study indicates that the activated sludge biomass is efficient in removing IBU/PARA and is a good alternative for the removal of these compounds from aqueous solutions. The removal was almost total for IBU and is high for PARA, which indicates that the maximum removal capacity of the biomass is far from being reached and could be used from the treatment of higher concentrations. Kinetic data of pharmaceuticals followed both, the pseudo-first order and pseudo-second order kinetic models. The comparison between biological and adsorption technologies shown better results, in general, for the biological method tested. QIA studies shown that the biomass seems not be negatively affected by the presence of both compounds. In fact, this biomass showed to be very resistant to the xenobiotic effect of pharmaceuticals, which is a good indication that can be used for the treatment of other compounds.

\section{Declaration of Competing interest}

The authors have no competing interests.

\section{Acknowledgments}

The authors thank the Portuguese Foundation for Science and Technology (FCT) under the scope of the strategic funding of UID/BIO/ 04469/2019 unit, COMPETE 2020 (POCI-01-0145-FEDER-006684) and BioTecNorte operation (NORTE-01-0145-FEDER-000004) funded by European Regional Development Fund under the scope of Norte2020 Programa Operacional Regional do Norte. 

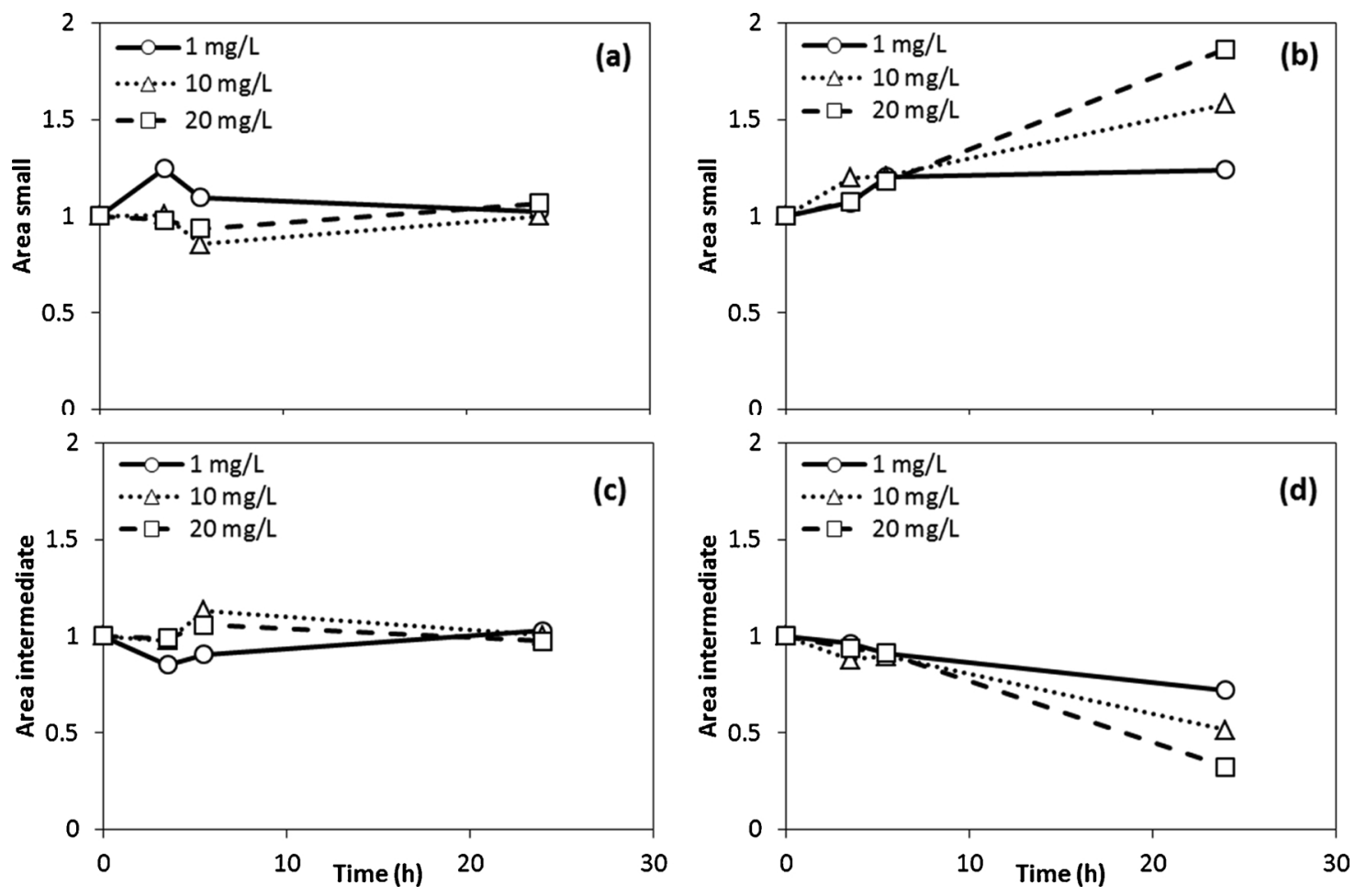

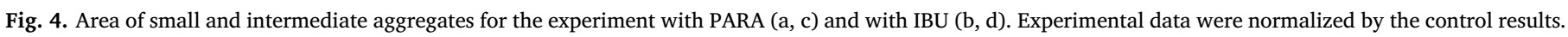
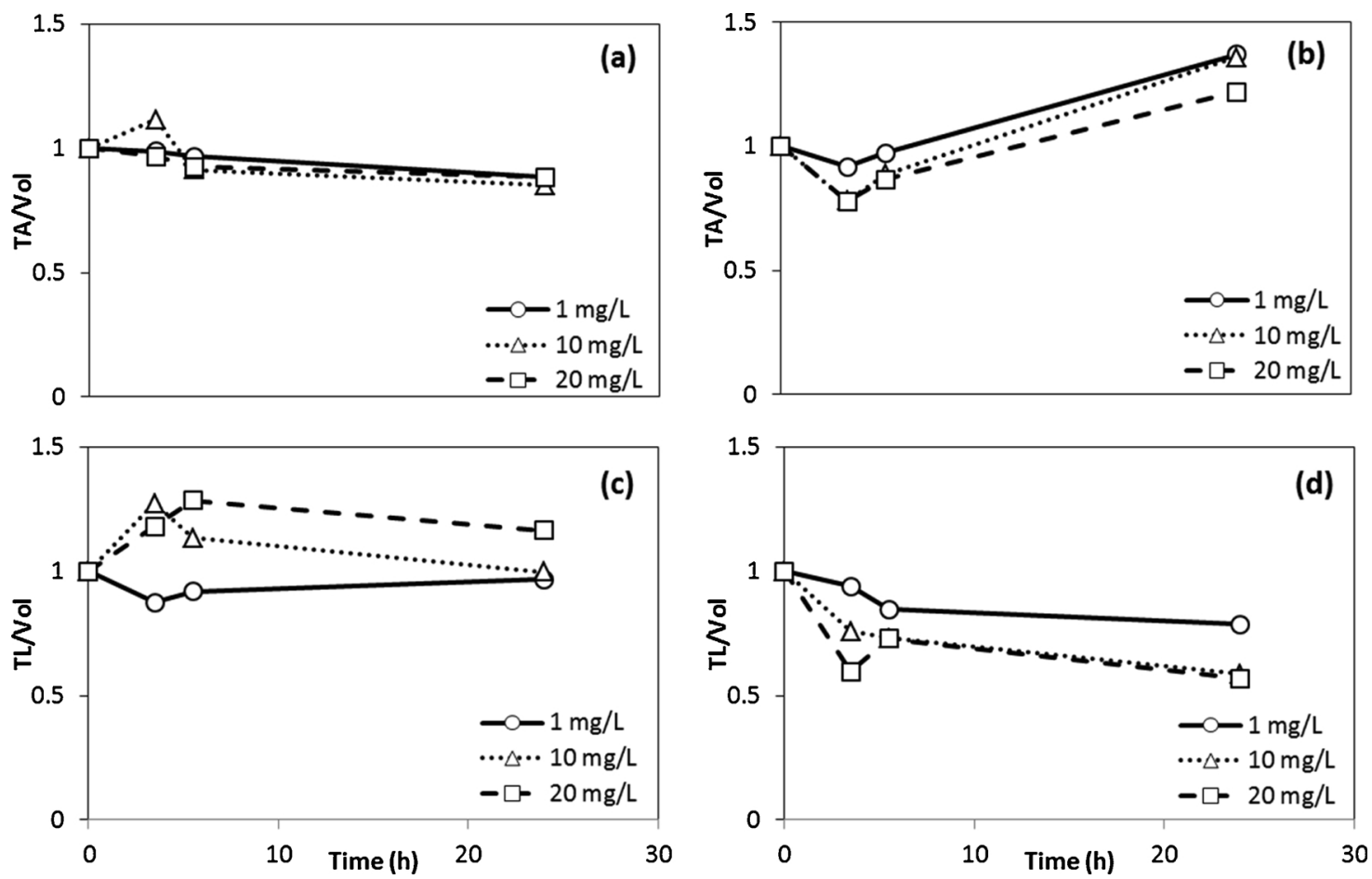

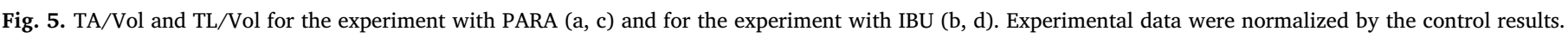

\section{Appendix A. Supplementary data}

Supplementary material related to this article can be found, in the online version, at doi:https://doi.org/10.1016/j.jwpe.2019.101061.

\section{References}

[1] P. Falas, A. Baillon-Dhumez, H.R. Andersen, A. Ledin, J. la Cour Jansen, Suspended biofilm carrier and activated sludge removal of acidic pharmaceuticals, Water Res. 46 (2012) 1167-1175.

[2] L. Proia, V. Osorio, S. Soley, M. Köck-Schulmeyer, S. Pérez, D. Barceló, A.M. Romaní, S. Sabater, Effects of pesticides and pharmaceuticals on biofilms in a highly impacted river, Environ. Pollut. 178 (2013) 220-228.

[3] Q. Sui, X. Cao, S. Lu, W. Zhao, Z. Qiu, G. Yu, Occurrence, sources and fate of pharmaceuticals and personal care products in the groundwater: a review, Emerg. Contam. 1 (2015) 14-24.

[4] S. Monteiro, A. Boxall, Occurrence and fate of human pharmaceuticals in the environment, in: D.M. Whitacre (Ed.), Reviews of Environmental Contamination and Toxicology, Springer, New York, NY, USA, 2010, pp. 53-154. 
[5] J. Zur, A. Piński, A. Marchlewicz, K. Hupert-Kocurek, D. Wojcieszyńska, U. Guzik, Organic micropollutants paracetamol and ibuprofen-toxicity, biodegradation, and genetic background of their utilization by bacteria, Environ. Sci. Pollut. Res. Int. 25 (2018) 21498-21524.

[6] EU Decision 495/2015, Commission implementing Decision (EU) 2015/495 of 20 March 2015 establishing a watch list of substances for Union-wide monitoring in the field of water policy pursuant to Directive 2008/105/EC of the European Parliament and of the Council, Off. J. Eur. Union L 78 (2015) 40-42.

[7] S. Yang, F.I. Hai, W.E. Price, J. McDonald, S.J. Khan, L.D. Nghiem, Occurrence of trace organic contaminants in wastewater sludge and their removals by anaerobic digestion, Bioresour. Technol. Rep. 210 (2016) 153-159.

[8] J. Radjenovic, M. Petrovic, D. Barceló, Analysis of pharmaceuticals in wastewater and removal using a membrane bioreactor, Anal. Bioanal. Chem. 387 (2007) 1365-1377.

[9] K. Gurung, M.C. Ncibi, M. Sillanpää, Removal and fate of emerging organic micropollutants (EOMs) in municipal wastewater by a pilot-scale membrane bioreactor (MBR) treatment under varying solid retention times, Sci. Total Environ. 667 (2019) 671-680.

[10] A. Dordio, R. Ferro, D. Teixeira, A.J. Palace, A.P. Pinto, C.M.B. Dias, Study on the use of Typha spp. for the phytotreatment of water contaminated with ibuprofen, Int. J. Environ. Anal. Chem. 91 (2011) 654-667.

[11] A. Marchlewicz, D. Domaradzka, U. Guzik, D. Wojcieszyńska, Bacillus thuringiensis B1(2015b) is a Gram-positive bacteria able to degrade naproxen and ibuprofen, Water Air Soil Pollut. 227 (197) (2016) 1-8.

[12] L.L. Zhang, J. Hu, R.Y. Zhu, Q.W. Zhou, J.M. Chen, Degradation of paracetamol by pure bacterial cultures and their microbial consortium, Appl. Microbiol. Biotechnol. 97 (2013) 3687-3698.

[13] L. Ferrando-Climent, N. Collado, G. Buttiglieri, M. Gros, I. Rodriguez-Roda, S. Rodriguez-Mozaz, D. Barceló, Comprehensive study of ibuprofen and its metabolites in activated sludge batch experiments and aquatic environment, Sci. Total Environ. 438 (2012) 404-413.

[14] A. Kruglova, P. Ahlgren, N. Korhonen, P. Rantanen, A. Mikola, R. Vahala, Biodegradation of ibuprofen, diclofenac and carbamazepine in nitrifying activated sludge under $12{ }^{\circ} \mathrm{C}$ temperature conditions, Sci. Total Environ. 499 (2014) 394-401.

[15] F.J. García-Mateos, R. Ruiz-Rosas, M.D. Marqués, L.M. Cotoruelo, J. RodríguezMirasol, T. Cordero, Removal of paracetamol on biomass-derived activated carbon: modeling the fixed bed breakthrough curves using batch adsorption experiments, Chem. Eng. J. 279 (2015) 18-30.

[16] A. Gil, N. Taoufik, A.M. García, S.A. Korili, Comparative removal of emerging contaminants from aqueous solution by adsorption on an activated carbon, Environ. Technol. 40 (2019) 3017-3030.

[17] F.G. Braga, S. Pinto, M.C.G. Antunes, Comparative study of $17 \beta$-estradiol removal from aqueous solutions using pine bark and almond shell as adsorbents, Microchim. Acta 173 (2011) 111-117.

[18] H. Khazri, I. Ghorbel-Abid, R. Kalfat, M. Trabelsi-Ayadi, Removal of ibuprofen, naproxen and carbamazepine in aqueous solution onto natural clay: equilibrium, kinetics, and thermodynamic study, Appl. Water Sci. (2016) 1-10.

[19] C.C. Emmanuel, O.I. Odigie, Adsorption of Acetaminophen from aqueous solutions onto hexadecyltrimethylammonium modified kaolinite, Nat. Sci. 12 (2014) 147-154.

[20] O. Chedeville, A. Di Giusto, S. Delpeux, B. Cagnon, Oxidation of pharmaceutical compounds by ozonation and ozone/activated carbon coupling: a kinetic approach, Desalin. Water Treat. 57 (2016) 18956-18963.

[21] N. Sabri, K. Hanna, V. Yargeau, Chemical oxidation of ibuprofen in the presence of iron species at near neutral pH, Sci. Total Environ. 427-428 (2012) 382-389.

[22] S. Wu, L. Zhang, J. Chen, Paracetamol in the environment and its degradation by microorganisms, Appl. Microbiol. Biotechnol. 96 (2012) 875-884.

[23] H. Bodin, A. Daneshvar, M. Gros, M. Hultberg, Effects of biopellets composed of microalgae and fungi on pharmaceuticals present at environmentally relevant levels in water, Ecol. Eng. 91 (2016) 169-172.

[24] N. Dorival-García, A. Zafra-Gómez, A. Navalón, J. González-López, E.J.L. Vílchez, Removal and degradation characteristics of quinolone antibiotics in laboratoryscale activated sludge reactors under aerobic, nitrifying and anoxic conditions, J. Environ. Manage. 120 (2013) 75-83.

[25] N. Collado, G. Buttiglieri, L. Ferrando-Climent, S. Rodriguez-Mozaz, D. Barceló, J. Comas, I. Rodriguez-Roda, Removal of ibuprofen and its transformation products: experimental and simulation studies, Sci. Total Environ. 433 (2012) 296-301.

[26] T. Backhaus, Medicines, shaken and stirred: a critical review on the ecotoxicology of pharmaceutical mixtures, Philos. Trans. Biol. Sci. 369 (20130585) (2014) 1-11.

[27] T. Brodin, S. Piovano, J. Fick, J. Klaminder, M. Heynen, M. Jonsson, Ecologica effects of pharmaceuticals in aquatic systems-impacts through behavioural alterations, Philos. Trans. Biol. Sci. 369 (20130580) (2014) 1-10.

[28] Z. Yan, X. Yang, G. Lu, J. Liu, Z. Xie, D. Wu, Potential environmental implications of emerging organic contaminants in Taihu Lake, China: Comparison of two ecotoxicological assessment approaches, Sci. Total Environ. 470-471 (2014) 171-179.

[29] T. Madureira, M.J. Rocha, C. Cruzeiro, I. Rodrigues, R. Monteiro, E. Rocha, The toxicity potential of pharmaceuticals found in the Douro River estuary (Portugal): Evaluation of impacts on fish liver, by histopathology, stereology, vitellogenin and CYP1A immunohistochemistry, after sub-acute exposures of the zebrafish model, Environ. Toxicol. Pharmacol. 34 (2012) 34-45.

[30] R. Oldenkamp, A.H.W. Beusen, M.A.J. Huijbregts, Aquatic risks from human pharmaceuticals-modelling temporal trends of carbamazepine and ciprofloxacin at the global scale, Environ. Res. Lett. 14 (2019) 1-11 034003.

[31] D.P. Mesquita, A.L. Amaral, E.C. Ferreira, Estimation of effluent quality parameters from an activated sludge system using quantitative image analysis, Chem. Eng. J.
285 (2016) 349-357.

[32] L. Nguyen, F. Ibney Hai, J. Kang, W.E. Price, L.D. Nghiem, Removal of emerging trace organic contaminants by MBR-based hybrid treatment processes, Int Biodeter. Biodegr. 85 (2013) 474-482.

[33] S. Khalaf, F. Al-Rimawi, M. Khamis, D. Zimmerman, U. Shuali, S. Nir, L. Scrano, S.A. Bufo, R. Karaman, Efficiency of advanced wastewater treatment plant system and laboratory-scale micelle-clay filtration for the removal of ibuprofen residues, $\mathrm{J}$. Environ. Sci. Health B 48 (2013) 814-821.

[34] A. Langenhoff, N. Inderfurth, T. Veuskens, G. Schraa, M. Blokland, K. KujawaRoeleveld, H. Rijnaarts, Microbial removal of the pharmaceutical compounds ibuprofen and diclofenac from wastewater, Biomed Res. Int. 2013 (2013) 1-9 325806.

[35] P. Paíga, L.H. Santos, C.G. Amorim, A.N. Araújo, M.C. Montenegro, A. Pena, C. Delerue-Matos, Pilot monitoring study of ibuprofen in surface waters of north of Portugal, Environ. Sci. Pollut. Res. 20 (2013) 2410-2420.

[36] G.J.F. Smolders, J. van de Meij, M.C.M. van Loosdrecht, J.J. Heijnen, Model of the anaerobic metabolism of the biological phosphorus removal process: stoichiometry and $\mathrm{pH}$ influence, Biotechnol. Bioeng. 43 (1994) 461-470.

[37] D.P. Mesquita, O. Dias, A.L. Amaral, E.C. Ferreira, A comparison between bright field and phase-contrast image analysis techniques in activated sludge morphological characterization, Microsc. Microanal. 16 (2010) 166-174.

[38] S. Matongo, G. Birungi, B. Moodley, P. Ndungu, Occurrence of selected pharmaceuticals in water and sediment of Umgeni River, KwaZulu-Natal, South Africa, Environ. Sci. Pollut. Res. 22 (2015) 10298-10308.

[39] A. Eslami, M.M. Amini, A.R. Yazdanbakhsh, N. Rastkari, A. Mohseni-Bandpei, S. Nasseri, E. Piroti, A. Asadi, Occurrence of non-steroidal anti-inflammatory drug in Tehran source water, municipal and hospital wastewaters, and their ecotoxicological risk assessment, Environ. Monit. Assess. 187 (734) (2015) 1-15.

[40] Z. Li, N. Fitzgerald, W.-T. Jiang, G. Lv, Palygorskite for the uptake and removal of pharmaceuticals for wastewater treatment, Process Saf. Environ. Prot. 101 (2016) $80-87$.

[41] T.V.N. Padmesh, K. Vijayaraghavan, G. Sekaran, M. Velan, Biosorption of acid blue 15 using fresh water macroalga Azolla filiculoides: batch and column studies, Dyes Pigm. 71 (2006) 77-82.

[42] C. Quintelas, F. Costa, T. Tavares, Bioremoval of diethylketone by the synergistic combination of microorganisms and clays: uptake, removal and kinetic studies, Environ. Sci. Pollut. Res. 20 (2013) 1374-1383.

[43] T.H. Yu, A.Y. Lin, S.C. Panchangam, P.K. Hong, P.Y. Yang, C.F. Lin, Biodegradation and bio-sorption of antibiotics and non-steroidal anti-inflammatory drugs using immobilized cell process, Chemosphere 84 (2011) 1216-1222.

[44] R. Andreozzi, M. Raffaele, P. Nicklas, Pharmaceuticals in STP effluents and their solar photodegradation in aquatic environment, Chemosphere 50 (2003) 1319-1330.

[45] M. Carballa, F. Omil, T. Ternes, J.M. Lema, Fate of pharmaceutical and personal care products (PPCPs) during anaerobic digestion of sewage sludge, Water Res. 41 (2007) 2139-2150.

[46] N. Nakada, T. Tanishima, H. Shinohara, K. Kiri, H. Takad, Pharmaceutical chemicals and endocrine disrupters in municipal wastewater in Tokyo and their removal during activated sludge treatment, Water Res. 40 (2006) 3297-3303.

[47] M.S. Fortunato, N.P. Fuentes Abril, M. Martinefski, V. Trípodi, M. Papalia, M. Rádice, G. Gutkind, A. Gallego, S.E. Korol, Aerobic degradation of ibuprofen in batch and continuous reactors by an indigenous bacterial community, Environ. Technol. 37 (2016) 2617-2626.

[48] C. Zwiener, S. Seeger, T. Glauner, F.H. Frimmel, Metabolites from biodegradation of pharmaceutical residues of ibuprofen in biofilm reactors and batch experiments, Anal. Bioanal. Chem. 372 (2002) 569-575.

[49] J.B. Quintana, S. Weiss, T. Reemtsma, Pathways and metabolites of microbial degradation of selected acidic pharmaceutical and their occurrence in municipal wastewater treated by membrane reactor, Water Res. 39 (2005) 2654-2664.

[50] A. Dordio, A.J. Palace Carvalho, D. Teixeira, C.M.B. Dias, A.P. Pinto, Removal of pharmaceuticals in microcosm constructed wetlands using Typha spp. and LECA, Bioresource Technol. 101 (2010) 886-892.

[51] N. Özengin, A. Elmaci, Removal of pharmaceutical products in a constructed wetland, Iran J. Biotech. 14 (2016) 221-229.

[52] M.C.G. Antunes, S. Pinto, F.G. Braga, J.C.G.E. Silva, Optimization of bisphenol A removal from water using chemically modified pine bark and almond shell, Chem. Ecol. 28 (2012) 141-152.

[53] S.K. Behera, S.Y. Oh, H.S. Park, Sorptive removal of ibuprofen from water using selected soil minerals and activated carbon, Int. J. Environ. Sci. Technol. (Tehran) 9 (2012) 85-94.

[54] C.M. García, T.C. Palomino, F.J.I. Godino, F.A.C. Iglesias, Porosity of expanded clay manufactured with addition of sludge from the brewing industry, Int. J. Energy Environ. Eng. 5 (2014) 341-347.

[55] K.V. Kumar, Linear and non-linear regression analysis for the sorption kinetics of methylene blue onto activated carbon, J. Hazard. Mater. B137 (2006) 1538-1544.

[56] H. Zhang, Y. Tang, D. Cai, X. Liu, X. Wang, Q. Huang, Z. Yu, Hexavalent chromium removal from aqueous solution by algal bloom residue derived activated carbon: equilibrium and kinetic studies, J. Hazard. Mater. 181 (2010) 801-808.

[57] A.E. Ofomaja, Biosorption studies of $\mathrm{Cu}(\mathrm{II})$ onto Mansonia sawdust: Process design to minimize biosorbent dose and contact time, React. Funct. Polym. 70 (2010) 879-889.

[58] S. Santaeufémia, E. Torres, J. Abalde, Biosorption of ibuprofen from aqueous solution using living and dead biomass of the microalga Phaeodactylum tricornutum, J. Appl. Phycol. 30 (2018) 471-482.

[59] A.L. Amaral, D.P. Mesquita, E.C. Ferreira, Automatic identification of activated sludge disturbances and assessment of operational parameters, Chemosphere 91 (2013) 705-710. 
[60] R. Jenné, E.N. Banadda, I.Y. Smets, J. Deurinck, J.F. Van Impe, Detection of filamentous bulking problems: developing an image analysis system for sludge composition monitoring, Microsc. Microanal. 13 (2007) 36-41.

[61] A.L. Amaral, E.C. Ferreira, Activated sludge monitoring of a wastewater treatment plant using image analysis and partial least squares regression, Anal. Chim. Acta 544 (2005) 246-253.

[62] J.R. Lawrence, B. Zhu, G.D.W. Swerhone, J. Roy, V. Tumber, M.J. Waiser, E. Topp, D.R. Korber, Molecular and microscopic assessment of the effects of caffeine, acetaminophen, diclorofenac, and their mixtures on river biofilm communities, Environ. Toxicol. Chem. 31 (2012) 508-517.

[63] A.B. Caracciolo, E. Topp, P. Grenni, Pharmaceuticals in the environment: biodegradation and effects on natural microbial communities. A review, J. Pharm. Biomed. Anal. 106 (2015) 25-36.

[64] A. Garcia-Rodríguez, V. Matamoros, C. Fontàs, V. Salvadó, The influence of Lemna $\mathrm{sp}$. and Spirogyra sp. on the removal of pharmaceuticals and endocrine disruptors in treated wastewaters, Int. J. Environ. Sci.Technol. 12 (2015) 2327-2338. 